\title{
Outcomes after emergency department use in patients with cancer receiving chemotherapy in Ontario, Canada: a population-based cohort study
}

\author{
Keerat Grewal MD MSc, Monika K. Krzyzanowska MD MPH, Shelley McLeod MSc PhD, \\ Bjug Borgundvaag MD PhD, Clare L. Atzema MD MSc
}

Abstract

Background: Patients with cancer frequently require emergency medical care during treatment. The objective of this study was to characterize emergency department visits made by patients with cancer receiving chemotherapy and to describe associated outcomes.

Methods: This retrospective cohort study used population-based administrative data from Ontario, Canada. Patients aged 18 years and older, with a cancer diagnosis, and who received chemotherapy in the 30 days before being seen in an emergency department between 2013 and 2017 were included. Emergency department discharge diagnosis codes were categorized to identify the most frequent emergency department diagnoses. We examined the proportion of patients admitted to hospital and 30 -day mortality. We used logistic regression to identify predictors of hospital admission.

Results: We identified 218459 emergency department visits made by 87555 patients. The median number of emergency department visits per patient was 2 (interquartile range 1-3). Hematological, gastrointestinal, breast and lung cancer were the most common malignancies represented. The most common emergency department diagnoses were infection or fever (57 036 [26.1\%]) and gastrointestinal diagnoses (26 456 [12.2\%]). Of all visits, 77978 (35.7\%) resulted in admission to hospital. Thirty-day mortality after an emergency department visit was $9.8 \%$. There was an increased odds of admission among patients who previously received palliative consultation, patients with bone or soft tissue or hematological malignancies, and patients with infection, gastrointestinal, pulmonary, cardiac, weakness or genitourinary and nephrology diagnoses.

Interpretation: Patients with cancer frequently used the emergency department during chemotherapy, and 1 in 4 emergency department visits were for infection or fever. These results highlight opportunities to optimize care for certain patients being actively treated for cancer, particularly around infectious complaints.

\begin{abstract}
- $t$ is estimated that half of all Canadians will develop cancer during their lifetime, ${ }^{1}$ and cancer is the leading cause of death in Canada. ${ }^{2}$ Although advances in treatments such as chemotherapy and radiation have improved survival among many patients with cancer, these treatments are not without substantial adverse effects and toxicities. ${ }^{3}$ Given these issues, it is not surprising that patients undergoing active cancer treatment are frequent users of the emergency department. ${ }^{4-6}$

Emergency department use is higher among patients with cancer than among the general population. A recent study from the United States using the Nationwide Emergency Department Sample estimated that patients with cancer account for around $4 \%$ of all emergency department visits in the US. ${ }^{7}$ Another US report that examined health insurance claims found that patients with cancer who were undergoing systemic therapy were seen in the emergency department an average of twice per year. ${ }^{6}$ In Canada, the Cancer Quality Council of Ontario reported that more than $40 \%$ of patients with colon or breast cancer who receive adjuvant chemotherapy are seen in the emergency department at least once within
\end{abstract}

4 weeks of chemotherapy. ${ }^{8}$ About $30 \%$ of these patients who are seen in the emergency department are admitted to hospital, and half will be seen in the emergency department a second or third time during active treatment. ${ }^{8}$

Previous studies have shown that fever, gastrointestinal complaints and pain are common reasons for which patients with cancer are seen in the emergency department or admitted to hospital. ${ }^{9-11}$ However, few studies have been conducted at a population level or report on Canadian data. The objective of this study was to describe, on a population-based level, the reasons why adult patients with cancer who are receiving chemotherapy are seen in the emergency department in

Competing interests: Monika Krzyzanowska has received grants from Eisia and Exelixis, and honoraria from Eisia and Bayer. No other competing interests were declared.

This article has been peer reviewed.

Correspondence to: Keerat Grewal, Keerat.grewal@sinaihealth.ca

CMAJ Open 2020. DOI:10.9778/cmajo.20190198 
Ontario, Canada, and to describe the outcomes associated with these emergency department visits.

\section{Methods}

\section{Study design and setting}

We conducted a retrospective cohort study of population-based health data from Ontario. Study patients and related information were obtained from province-wide health administrative databases held at ICES. ICES is an independent, nonprofit research institute that collects and analyzes health care and demographic data, for health system evaluation and improvement.

\section{Data sources}

Patients with cancer were identified from the Ontario Cancer Registry. The Ontario Cancer Registry contains information on all diagnosed cases of cancer in Ontario (except basal and squamous cell skin cancers). Data regarding chemotherapy were obtained from the Cancer Activity Level Reporting database, the New Drug Funding Program database, and claims for the supervision of chemotherapy in the Ontario Health Insurance Plan (OHIP) database. Data regarding radiation were obtained from the Cancer Activity Level Reporting database.

Emergency department visits were identified from the Canadian Institute for Health Information (CIHI) National Ambulatory Care Reporting System, an administrative database that contains anonymized, abstracted data on all emergency department patient visits in the province of Ontario. The CIHI's Discharge Abstract Database contains information on all acute care hospital admissions in the province. The OHIP database contains all physician billings for medically necessary care. The Registered Persons Database contains mortality information for all Ontario residents, including out-of-hospital deaths. These data sets were linked using unique encoded identifiers and analyzed at ICES. Ontario has universal health care coverage for medically necessary care, and therefore, these databases contain a large majority of the information about health care use in the province. See Appendix 1 (available at www.cmajopen.ca/ content/8/3/E496/suppl/DC1) for further description of the databases used for this study.

\section{Study participants}

Adult patients aged 18 years and older with a cancer diagnosis were identified from the Ontario Cancer Registry if they had a valid OHIP health card number. We then identified patients who received chemotherapy from the Cancer Activity Level Reporting Database, New Drug Funding Program database and the OHIP database in the 30 days before an emergency department visit between Jan. 1, 2013, and June 30, 2017. All emergency department visits (whether cancer-related or not) within 30 days of chemotherapy were identified from the National Ambulatory Care Reporting System. See Appendix 1 for further description of codes used to identify patients receiving chemotherapy.
We excluded visits in an Ontario emergency department that was not open 24 hours per day or visits to an urgent care centre (as these typically see a patient population with much lower acuity than a true emergency department), visits that resulted in the patient leaving the emergency department without being seen by a health care provider or leaving against medical advice, and visits with missing emergency department diagnoses. We also excluded emergency department visits for which the main diagnosis for the emergency department visit was listed as radiation or chemotherapy to ensure that scheduled visits for chemotherapy or radiation were not included in our analysis.

\section{Outcome variables}

The primary outcome of interest was the emergency department diagnosis. We classified the primary emergency department diagnoses into general categories based on the International Statistical Classification of Diseases and Related Health Problems, 10th Revision (ICD-10) codes. If the primary emergency department diagnosis was a broad "cancer" diagnosis, the second and third emergency department diagnosis and chief complaint were assessed to ascertain the reason for the emergency department visit. If we were still unable to determine a main emergency department diagnosis by this method, the diagnosis was left as "cancer."

We identified more than 30 categories of diagnoses. These categories included infection or fever (e.g., sepsis, pneumonia, urinary tract infections, cellulitis, fever and neutropenia); gastrointestinal diagnoses (e.g., varices, ulcers, gastrointestinal bleed and obstruction); pain (e.g., abdominal pain, headache and any pain-related diagnosis); hematological diagnoses (e.g., anemias and thrombocytopenias); pulmonary diagnoses (e.g., dyspnea, pulmonary hypertension, chronic obstructive pulmonary disease and pleural effusion); thrombosis and others. See Appendix 1, Supplementary Table 1 for categorization of ICD-10 codes.

Secondary outcomes included the proportion of emergency department visits resulting in admission to hospital; 30-day mortality after an emergency department visit; and identification of variables associated with hospital admission.

\section{Covariates}

To identify variables associated with hospital admission, the following covariates were included in a multivariable model to predict hospital admission: demographic characteristics (age, sex, neighbourhood income quintile); cancer-related variables (cancer type categorized based on International Classification of Diseases for Oncology [ICD-O] codes, radiation in the 90 days before emergency department visit); receipt of palliative consultation before the emergency department visit; and emergency department visit characteristics (ambulance arrival, triage acuity based on the Canadian Triage and Acuity Scale, time of emergency department visit [day, evening or night], day of emergency department visit [weekday or weekend], emergency department diagnosis and hospital type [small, community or academic]). See Appendix 1 for further description and definitions of covariates. 


\section{Statistical analysis}

We determined the total number of emergency department visits by unique patients during the study period and used descriptive statistics to characterize unique patients based on their first emergency department encounter. All emergency department visits were then described using frequencies and percentages for categorical data and medians and interquartile ranges (IQRs) for continuous variables. We described emergency department visits resulting in admission versus discharge, removing from the regression model patients who died in the emergency department, because these patients would not be available for the outcome of admission or discharge from the emergency department.

To examine the adjusted association of the above-listed covariates with admission to hospital, we conducted a multivariable logistic regression model using generalized estimating equations with an exchangeable correlation structure to account for clustering at the patient level from repeat visits. We assessed the correlation coefficient to determine the effect of clustering within individuals. We calculated the unadjusted and adjusted odds ratios with $95 \%$ confidence intervals. All analyses were conducted using SAS 9.3 (SAS).

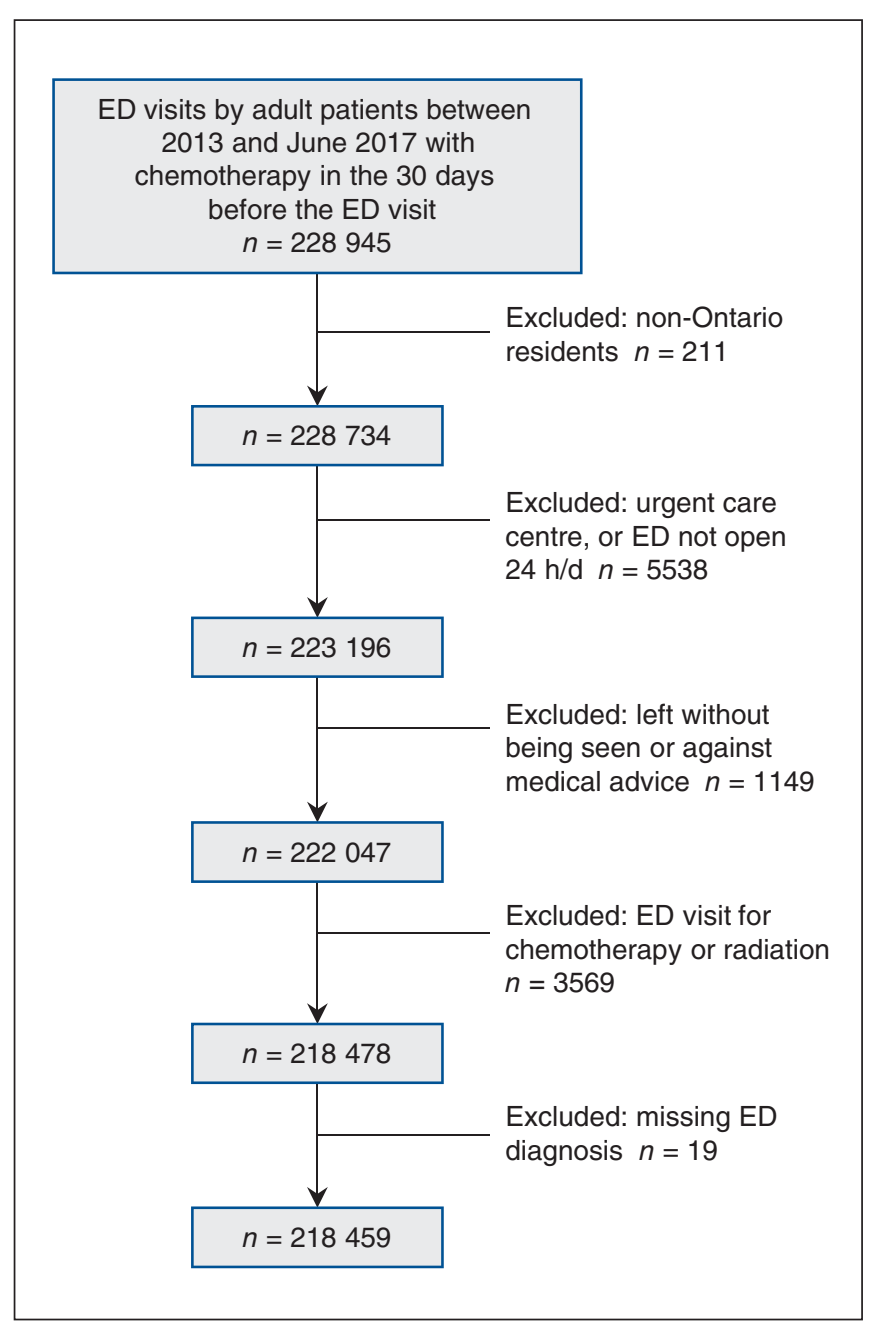

Figure 1: Study flow diagram. Note: ED = emergency department.

\section{Ethics approval}

This study received privacy approval from ICES and ethics approval from the research ethics board at Sinai Health System.

\section{Results}

There were 222945 emergency department visits by patients within 30 days of receiving chemotherapy during the study period. After exclusions, a total of 87555 unique patients made 218459 emergency department visits within 30 days of receiving chemotherapy during the study period and were included in the study (Figure 1). Table 1 contains the baseline characteristics of the cohort. The median age of patients was 66 (IQR 56-74) years and the median number of emergency department visits per patient was 2 (IQR 1-3).

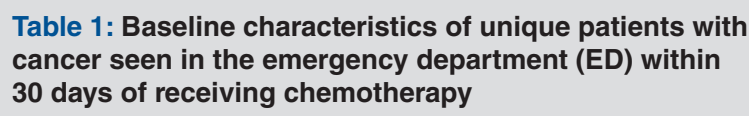

$\begin{array}{cc} & \begin{array}{c}\text { No. of unique } \\ \text { patients }\end{array} \\ n=87555\end{array}$

Age, yr, median (IQR) $66(56-74)$

No. of ED visits within $30 \mathrm{~d}$ of chemotherapy

\begin{tabular}{|cc}
\hline Median $(\mathrm{IQR})$ & $2(1-3)$ \\
\hline 90th percentile & 6
\end{tabular}

Sex, female $48172(55.0)$

Rural 13604 (15.5)

Income quintile

\begin{tabular}{|lc|}
\hline 1 (highest) & $15674(18.0)$ \\
\hline 2 & $17145(19.6)$ \\
\hline 3 & $17543(20.1)$ \\
\hline 4 & $18701(21.4)$ \\
\hline 5 (lowest) & $18200(20.9)$ \\
\hline Cancer type & $17857(20.4)$ \\
\hline Gastrointestinal & $17288(19.8)$ \\
\hline Breast & $16834(19.2)$ \\
\hline Hematological & $11732(13.4)$ \\
\hline Lung & $5322(6.1)$ \\
\hline Gynecological & $4811(5.5)$ \\
\hline Male genital & $3720(4.3)$ \\
\hline Head and neck & $3241(3.7)$ \\
\hline Genitourinary & $2065(2.4)$ \\
\hline Neurological & $1908(2.2)$ \\
\hline Melanoma & $972(1.1)$ \\
\hline Bone or soft tissue & $81(0.1)$ \\
\hline Endocrine & $1706(2.0)$ \\
\hline Other & \\
\hline $\begin{array}{l}\text { Note: IQR = interquartile range. } \\
* \text { Unless stated otherwise. }\end{array}$ \\
\hline
\end{tabular}


The most common emergency department diagnosis was infection or fever (57 036 [26.1\%] emergency department visits). In the infectious or fever diagnostic category, the most common diagnoses included fever not yet diagnosed, neutropenia, lower respiratory tract infections, genitourinary infections and skin or soft tissue infections. The next most frequent emergency department diagnoses were gastrointestinal (26 456 [12.1\%]) and pain-related diagnoses (22 135 [10.1\%]). See Table 2 and Figure 2 for the top 10 emergency department diagnoses.

More than half (124 709 [57.3\%]) of the emergency department visits occurred during daytime hours (8:0016:59). In total, 93098 (42.6\%) of the emergency department visits involved a specialty consultation in the emergency department, and 77978 (35.7\%) emergency department visits resulted in hospital admission. The overall median emergency department length of stay was 5.3 (IQR 3.0-9.8) hours. For patients discharged from the emergency department, the median emergency department length of stay was 3.9 (IQR 2.3-6.0) hours, and for patients admitted to the hospital, the median length of stay was 11.3 (IQR 6.621.0) hours. Thirty-day mortality after an emergency department visit was $9.8 \%$.

Emergency department visits by patients with hematological malignancies (47 207 visits) were the most common, followed by gastrointestinal cancers (45 626 visits), breast cancer (38 914 visits) and lung cancer (27 710 visits). Infection or fever was the most common emergency department diagnosis for all cancers. Table 3 shows the top 3 emergency department diagnoses for hematological, gastrointestinal, breast and lung cancers. Patients with bone or soft tissue cancer had the highest $(41.1 \%)$ proportion of admissions, whereas patients with breast cancer had the lowest (27.4\%) admissions.

Of all patients, $648(0.3 \%)$ patients died in the emergency department, leaving 217811 emergency department visits for analysis of predictors of admission. The characteristics of emergency department visits resulting in admission versus discharge for these patients are presented in Table 4 . In the adjusted analysis, emergency department visits with a diagnosis of infection or fever, gastrointestinal diagnoses, pulmonary diagnoses, cardiac diagnoses, weakness or genitourinary and nephrology diagnoses had an increased odds of hospital admission compared with those with a diagnosis of pain (Table 5). Conversely, those with a device problem were significantly less likely to be admitted. Emergency department visits made by patients older than 65 years, patients who had received radiation, and patients who received palliative care were more likely to result in admission. Emergency department visits at a community or academic hospital had an increased odds of admission compared with smaller hospital sites. Compared with patients with gastrointestinal cancer, patients with bone or soft tissue and hematological malignancies had an increased odds of admission, whereas those with gynecological, head and neck, and breast cancer were less likely to be admitted to hospital.

\section{Interpretation}

In this study, there were more than 200000 emergency department visits made in the province of Ontario by patients with cancer receiving chemotherapy over 4.5 years. More than a third of these visits resulted in hospital admission.

\begin{tabular}{|c|c|c|c|}
\hline \multirow[b]{2}{*}{ ED diagnosis } & \multicolumn{3}{|c|}{ No. (\%) of visits } \\
\hline & $\begin{array}{c}\text { Total ED visits } \\
n=218459\end{array}$ & $\begin{array}{l}\text { Hospital admission } \\
n=77978 \\
(35.7 \%)^{*}\end{array}$ & $\begin{array}{l}\text { 30-day mortality } \\
n=21333 \\
(9.8 \%)^{*}\end{array}$ \\
\hline Infection or fever & $57036(26.1)$ & $26060(45.6)$ & $3900(6.8)$ \\
\hline Gastrointestinal & $26456(12.1)$ & $11490(43.4)$ & $2578(9.7)$ \\
\hline Pain & $22135(10.1)$ & $4744(21.4)$ & $1664(7.5)$ \\
\hline Injury or MSK† & $14971(6.8)$ & $2220(14.8)$ & $639(4.2)$ \\
\hline Pulmonary & $12492(5.7)$ & $5406(43.2)$ & $2319(18.5)$ \\
\hline Cardiac & $9870(4.6)$ & $4613(46.7)$ & $923(9.3)$ \\
\hline Weakness, social issues & $9814(4.4)$ & $5131(52.2)$ & $2377(24.2)$ \\
\hline Related to device, graft or stoma & $7176(3.2)$ & $588(8.1)$ & $310(4.3)$ \\
\hline III-defined complaints & $6585(3.0)$ & $355(5.3)$ & $308(4.6)$ \\
\hline Genitourinary and nephrology & $6280(2.8)$ & $2280(36.3)$ & $644(10.2)$ \\
\hline Other & $45644(20.8)$ & $15091(33.0)$ & $5671(12.4)$ \\
\hline \multicolumn{4}{|c|}{$\begin{array}{l}\text { Note: MSK = musculoskeletal. } \\
\text { *Percentages in these columns reflect the proportion of ED visits for that diagnosis resulting in hospital admission or 30-day } \\
\text { mortality. } \\
\text { †Includes fractures, dislocations, injuries (e.g., trauma, lacerations), sprains, strains, etc. }\end{array}$} \\
\hline
\end{tabular}




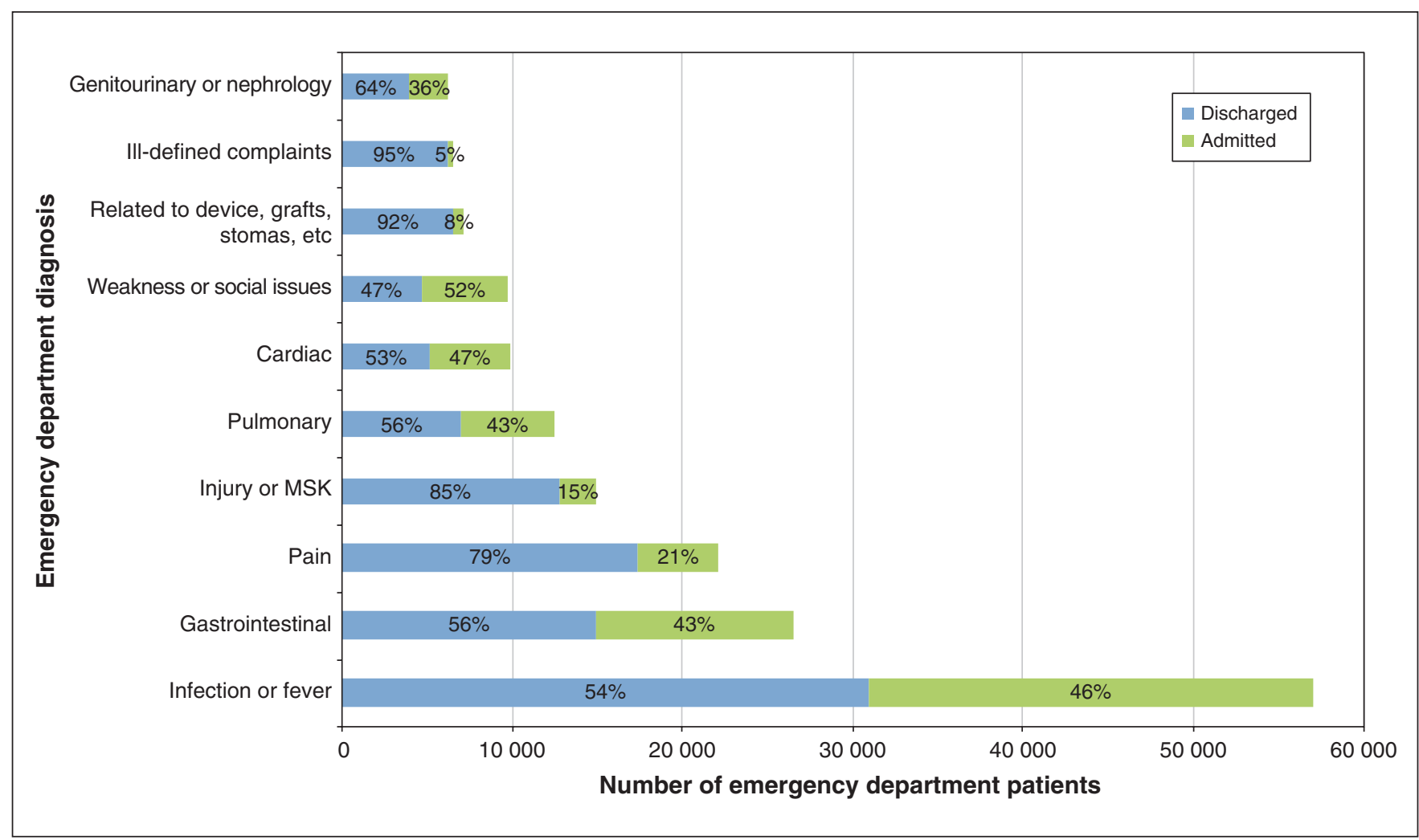

Figure 2: Top 10 emergency department diagnoses. Note: $\mathrm{MSK}=$ musculoskeletal.

By comparison, in the general population, the proportion of emergency department visits resulting in hospital admission in Ontario in the $2017 / 18$ fiscal year was $12 \% .{ }^{12}$ The higher number of admissions for patients with cancer in our study is consistent with that in previous literature, which has shown that the proportion of emergency department visits resulting in hospital admission among patients with cancer is significantly higher than among the general population..$^{13}$ The proportion of hospital admissions found in our study was lower than that in other studies from the US, which have reported that $50 \%$ to $90 \%$ of emergency department visits among patients with active cancer result in hospital admission. ${ }^{7,14,15}$ Two of these US studies examined emergency department visits that were cancer-related ${ }^{7}$ or treatment-related, ${ }^{14}$ whereas we examined all-cause emergency department visits by patients with cancer. The different type of emergency department visits examined in the studies may account for some of the disparity in admissions. This variability may also be related to different health care systems between the 2 countries: higher rates of hospital admission have been shown for other diseases in the US versus comparable countries based on GDP.

We found that 1 in 4 (26.1\%) emergency department visits were due to infection or fever, and it remained the most common emergency department diagnosis across all types of cancers. This finding is in keeping with previous literature, which has shown that infection, fever and febrile neutropenia are among the most frequent reasons for emergency department use among patients with cancer. . $^{7,-11,14,17}$ We also found that $45.7 \%$ of emergency department visits related to infection or

\begin{tabular}{|c|c|c|}
\hline \multirow[b]{2}{*}{ Diagnosis } & \multicolumn{2}{|c|}{ No. (\%) of visits } \\
\hline & Total ED visits & $\begin{array}{c}\text { Hospital } \\
\text { admission* }\end{array}$ \\
\hline \multicolumn{3}{|c|}{ Hematological cancer ( $n=47207$ ED visits) } \\
\hline Infection & $15460(32.7)$ & $8101(52.3)$ \\
\hline Injury or MSK & $3940(8.3)$ & $612(15.5)$ \\
\hline Pain & $3901(8.2)$ & $735(18.8)$ \\
\hline \multicolumn{3}{|c|}{ Gastrointestinal cancer ( $n=45626$ ED visits) } \\
\hline Infection & $10618(23.2)$ & $4577(43.1)$ \\
\hline Gastrointestinal & $8822(19.3)$ & $4516(51.1)$ \\
\hline Pain & $5130(11.2)$ & $1254(24.4)$ \\
\hline \multicolumn{3}{|c|}{ Breast cancer ( $n=38914$ ED visits) } \\
\hline Infection & $11158(28.6)$ & $3931(35.2)$ \\
\hline Pain & $4564(11.7)$ & $741(16.2)$ \\
\hline Gastrointestinal & $3680(9.4)$ & $1209(32.8)$ \\
\hline \multicolumn{3}{|c|}{ Lung cancer ( $n=27710$ ED visits) } \\
\hline Infection & $6551(23.6)$ & $3357(51.2)$ \\
\hline Pulmonary & 3298 (11.9) & $1690(51.2)$ \\
\hline Gastrointestinal & $2697(9.7)$ & $951(35.2)$ \\
\hline $\begin{array}{l}\text { Note: } \text { MSK = musculosk } \\
{ }^{*} \text { Percentages in this col } \\
\text { resulting in hospital adm }\end{array}$ & he proportion of & r that diagnosis \\
\hline
\end{tabular}




\begin{tabular}{|c|c|c|c|c|}
\hline Variable & $\begin{array}{c}\text { Total ED visits } \\
n=217811\end{array}$ & $\begin{array}{l}\text { Discharged } \\
n=139833\end{array}$ & $\begin{array}{c}\text { Admitted } \\
n=77978\end{array}$ & Difference $(95 \% \mathrm{Cl})$ \\
\hline \multicolumn{5}{|l|}{ Demographic characteristics } \\
\hline Age $\geq 65 \mathrm{yr}$ & $116871(53.6)$ & $72501(51.8)$ & 44370 (56.9) & $-5.1(-5.5$ to -4.6$)$ \\
\hline Sex, female & $117894(54.1)$ & $78071(55.8)$ & $39823(51.1)$ & 4.8 (4.3 to 5.2$)$ \\
\hline \multicolumn{5}{|l|}{ Income quintile } \\
\hline 1 (highest) & 40935 (18.7) & $26343(18.8)$ & $14592(18.7)$ & $0.1(-0.2$ to 0.5$)$ \\
\hline 2 & $42519(19.5)$ & $27209(19.5)$ & $15310(19.6)$ & $-0.2(-0.5$ to 0.2$)$ \\
\hline 3 & 43469 (19.9) & $27883(19.9)$ & $15586(20.0)$ & $-0.1(-0.4$ to 0.3$)$ \\
\hline 4 & $46048(21.1)$ & $29543(21.1)$ & $16505(21.2)$ & $0(-0.4$ to 0.3$)$ \\
\hline 5 (lowest) & $44019(20.2)$ & $28303(20.2)$ & $15716(20.2)$ & $0.1(-0.3$ to 0.4$)$ \\
\hline Missing & $821(0.3)$ & $552(0.4)$ & $269(0.3)$ & \\
\hline \multicolumn{5}{|l|}{ Cancer characteristics } \\
\hline Palliative care & $110061(50.5)$ & $64368(46.0)$ & $45693(58.6)$ & $-12.6(-13.0$ to -12.1$)$ \\
\hline Radiation $90 \mathrm{~d}$ before ED visit & $31041(14.2)$ & $18375(13.1)$ & 12 666(16.2) & $3.1(-3.4$ to -2.8$)$ \\
\hline \multicolumn{5}{|l|}{ Cancer type } \\
\hline Hematological & $47086(21.6)$ & $29254(20.9)$ & $17832(22.9)$ & $-2.0(-2.3$ to 1.6$)$ \\
\hline Gastrointestinal & $45467(20.8)$ & $28841(20.6)$ & $16626(21.3)$ & $-0.7(-1.0$ to -0.3$)$ \\
\hline Breast & 38867 (17.8) & $28210(20.2)$ & $10657(13.7)$ & 6.5 (6.2 to 6.8$)$ \\
\hline Lung & $27558(12.6)$ & $16202(11.6)$ & 11356 (14.6) & $-3.0(-3.3$ to -2.7$)$ \\
\hline Gynecological & $13806(6.3)$ & $8961(6.4)$ & $4845(6.2)$ & $0.2(0$ to 0.4$)$ \\
\hline Male genital & $12347(5.6)$ & $7948(5.7)$ & $4399(5.6)$ & $0(-0.2$ to 0.2$)$ \\
\hline Genitourinary & $8352(3.8)$ & $5279(3.8)$ & 3037 (3.9) & $-0.1(-0.3$ to 0$)$ \\
\hline Head and neck & $8110(3.7)$ & $5275(3.8)$ & $2835(3.6)$ & 0.1 (0 to 0.3$)$ \\
\hline Neurological & $4826(2.2)$ & $2866(2.0)$ & $1960(2.5)$ & $-0.5(-0.6$ to -0.3$)$ \\
\hline Melanoma & $4496(2.0)$ & $2821(2.0)$ & $1675(2.2)$ & $-0.1(-0.3$ to 0$)$ \\
\hline Bone or soft tissue & $2636(1.2)$ & $1550(1.1)$ & $1086(1.4)$ & $-0.3(-0.4$ to -0.2$)$ \\
\hline Endocrine & $216(0.1)$ & $133(0.1)$ & $83(0.1)$ & $0(0)$ \\
\hline Other & $4003(1.8)$ & $2474(1.8)$ & $1529(2.0)$ & $-0.2(-0.3$ to -0.1$)$ \\
\hline Missing & $41(0.02)$ & $19(0.0)$ & $22(0.0)$ & \\
\hline \multicolumn{5}{|l|}{ ED visit characteristics } \\
\hline Ambulance arrival & $54077(24.8)$ & $21649(15.5)$ & 32428 (41.6) & $-26.1(-26.5$ to -25.7$)$ \\
\hline \multicolumn{5}{|l|}{ CTAS } \\
\hline 1-2 (highest acuity) & 91345 (41.9) & $45260(32.4)$ & $46085(59.1)$ & $-26.7(-27.2$ to -26.3$)$ \\
\hline 3 & 97688 (44.9) & $67776(48.5)$ & $29912(38.4)$ & $10.1(9.7$ to 10.5$)$ \\
\hline 4-5 (lowest acuity) & $28341(13.0)$ & 26444 (18.9) & $1897(2.4)$ & 16.5 (16.3 to 16.7$)$ \\
\hline Missing & $437(0.2)$ & $353(0.3)$ & $84(0.1)$ & \\
\hline \multicolumn{5}{|l|}{ Shift } \\
\hline Day (8:00-16:59) & 124709 (57.3) & 82721 (59.2) & 41988 (53.9) & 5.3 (4.9 to 5.8$)$ \\
\hline Evening (17:00-23:59) & $67176(30.8)$ & $41273(29.5)$ & 25903 (33.2) & $-3.7(-4.1$ to -3.3$)$ \\
\hline Night (0:00-7:59) & 25926 (11.9) & $15839(11.3)$ & 10087 (12.9) & $-1.6(-1.9$ to -1.3$)$ \\
\hline Weekend & $60248(27.7)$ & $39540(28.3)$ & $20708(26.6)$ & 1.7 (1.3 to 2.1$)$ \\
\hline
\end{tabular}




\begin{tabular}{|c|c|c|c|c|}
\hline Variable & $\begin{array}{c}\text { Total ED visits } \\
n=217811\end{array}$ & $\begin{array}{l}\text { Discharged } \\
n=139833\end{array}$ & $\begin{array}{c}\text { Admitted } \\
n=77978\end{array}$ & Difference $(95 \% \mathrm{Cl})$ \\
\hline \multicolumn{5}{|l|}{ ED visit characteristics cont'd } \\
\hline \multicolumn{5}{|l|}{ Hospital type } \\
\hline Small & $18145(8.3)$ & $14825(10.6)$ & $3320(4.3)$ & $6.3(6.1$ to 6.6$)$ \\
\hline Community & $136384(62.6)$ & $90163(64.5)$ & $46221(59.3)$ & $5.2(4.8$ to 5.6$)$ \\
\hline Academic & $63240(29.0)$ & 34829 (24.9) & $28411(36.4)$ & $-11.5(-11.9$ to -11.1$)$ \\
\hline Missing & $42(0.0)$ & $16(0.0)$ & $26(0.0)$ & \\
\hline \multicolumn{5}{|l|}{ ED diagnosis } \\
\hline Pain & $22123(10.2)$ & $17379(12.4)$ & $4744(6.1)$ & $6.3(6.1$ to 6.6$)$ \\
\hline Infection or fever & $56994(26.2)$ & 30934 (22.1) & $26060(33.4)$ & $-11.3(-11.7$ to -10.9$)$ \\
\hline Gastrointestinal & $26432(12.1)$ & $14942(10.7)$ & $11490(14.7)$ & $-4.0(-4.4$ to -3.8$)$ \\
\hline Injury or MSK & $14964(6.9)$ & $12744(9.1)$ & $2220(2.9)$ & $6.3(6.1$ to 6.5$)$ \\
\hline Pulmonary & $12429(5.7)$ & $7023(5.0)$ & $5406(6.9)$ & $-1.9(-2.1$ to -1.7$)$ \\
\hline Cardiac & $9818(4.5)$ & $5205(3.7)$ & $4613(5.9)$ & $-2.2(-2.4$ to -2.0$)$ \\
\hline Weakness, social issues & $9783(4.5)$ & 4652 (3.3) & $5131(6.6)$ & $-3.3(-3.5$ to -3.1$)$ \\
\hline Related to device or graft & 7175 (3.3) & $6587(4.7)$ & $588(0.8)$ & 4.0 (3.8 to 4.1$)$ \\
\hline III-defined & $6582(3.0)$ & $6227(4.5)$ & $355(0.5)$ & 4.0 (3.9 to 4.1$)$ \\
\hline Genitourinary and nephrology & $6278(2.9)$ & $3998(2.9)$ & $2280(2.9)$ & $-0.1(-0.2$ to 0$)$ \\
\hline None of top 10 diagnoses & $45233(20.8)$ & $30142(21.6)$ & $15091(19.4)$ & 2.2 (1.9 to 2.6$)$ \\
\hline
\end{tabular}

fever resulted in hospital admission, and infection or fever had the highest odds of hospital admission, which is consistent with previous studies. ${ }^{7,14}$

There is increasing interest in the area of potentially preventable emergency department visits among patients with cancer, ${ }^{18,19}$ and the high number of emergency department visits for infection or fever highlights the need for validated risk stratification tools for patients with cancer to determine which febrile patients require an emergency department visit. Previous studies have shown that some lowrisk febrile patients with neutropenia can be safely managed with oral antibiotics. ${ }^{20,21}$ Future work should focus on determining which patients with infection or fever can safely avoid an emergency department visit (e.g., patients with nonsystemic infections such as cellulitis or otitis media) and the best non-emergency department setting to be safely worked-up and treated.

Gastrointestinal diagnoses and emergency department visits for pain were also common in the cohort, each accounting for more than $10 \%$ of all emergency department visits. While more than $40 \%$ of gastrointestinal diagnoses resulted in hospital admission, only $20 \%$ of visits for pain resulted in hospital admission. The low number of admissions for emergency department visits associated with pain is promising; health care practitioners are able to offer acceptable outpatient management for pain-related emergency department visits in order to avoid hospital admission. However, based on the high number of emergency department visits related to pain, it is important to understand why patients with cancer who complain of pain require the emergency department services in the first place. Increased access to palliative care for pain control and discussions surrounding pain control with the patient's primary care physician or specialist may reduce emergency department visits related to pain. Furthermore, future research and guidelines for treating cancer-related pain in the emergency department may be useful.

We found that more than half of emergency department visits occurred during daytime hours. During daytime hours, cancer centres are typically open and may be able to see patients on an urgent basis through an urgent care clinic. This would allow for continuity of care in a setting where the patient and their course of illness is known to providers. Furthermore, some patients may be better treated in an urgent care clinic setting, where they may avoid wait times and potential exposure to infectious pathogens commonly encountered in the emergency department. The number of emergency department visits during daytime hours highlights an important opportunity for future research to examine the availability and outcomes associated with urgent care clinic use by patients with cancer.

\section{Limitations}

There are several limitations of this study. This study examined emergency department use by patients within the province of 
Ontario; therefore, the findings may not be generalizable outside of Ontario. We examined a heterogeneous group of patients with various cancers who were receiving different treatment regimens. Future studies are needed to determine whether our findings are specific to certain treatment regimens. In addition, this study used administrative data and there may be potential misclassification bias if there were coding errors for the variables used in this study, including the main diagnosis.

\begin{tabular}{|c|c|c|}
\hline Variable & $\begin{array}{l}\text { Unadjusted OR } \\
\qquad(95 \% \mathrm{Cl})\end{array}$ & $\begin{array}{l}\text { Adjusted OR* } \\
\quad(95 \% \mathrm{Cl})\end{array}$ \\
\hline \multicolumn{3}{|l|}{ Age, yr } \\
\hline$<65$ & Ref. & Ref. \\
\hline$\geq 65$ & 1.27 (1.25 to 2.30$)$ & $1.14(1.11$ to 1.16$)$ \\
\hline \multicolumn{3}{|l|}{ Sex } \\
\hline Male & Ref. & Ref. \\
\hline Female & 0.80 (0.78 to 0.82$)$ & 0.96 (0.93 to 0.98$)$ \\
\hline \multicolumn{3}{|l|}{ Income quintile } \\
\hline 1 (highest) & Ref. & Ref. \\
\hline 2 & 1.03 (1.00 to 1.07$)$ & 1.01 (0.98 to 1.05$)$ \\
\hline 3 & 1.04 (1.01 to 1.07$)$ & 0.99 (0.96 to 1.03$)$ \\
\hline 4 & $1.02(0.99$ to 1.05$)$ & 0.99 (0.95 to 1.02$)$ \\
\hline 5 (lowest) & 1.01 (0.98 to 1.04$)$ & 0.95 (0.92 to 0.99$)$ \\
\hline Palliative care & 1.73 (1.69 to 1.76$)$ & $1.48(1.44$ to 1.51$)$ \\
\hline Radiation $90 \mathrm{~d}$ before ED visit & 1.25 (1.22 to 1.29$)$ & 1.09 (1.06 to 1.12$)$ \\
\hline \multicolumn{3}{|l|}{ Cancer type } \\
\hline Gastrointestinal & Ref. & Ref. \\
\hline Hematological & 1.05 (1.02 to 1.09$)$ & 1.13 (1.09 to 1.17$)$ \\
\hline Breast & $0.62(0.60$ to 0.64$)$ & $0.77(0.74$ to 0.80$)$ \\
\hline Lung & 1.23 (1.19 to 1.27$)$ & $1.00(0.96$ to 1.04$)$ \\
\hline Gynecological & 0.91 (0.87 to 0.95$)$ & $0.92(0.88$ to 0.97$)$ \\
\hline Male genital & $0.96(0.91$ to 1.01$)$ & $0.95(0.90$ to 1.00$)$ \\
\hline Genitourinary & $1.01(0.96$ to 1.07$)$ & $0.98(0.92$ to 1.04$)$ \\
\hline Head and neck & $0.91(0.86$ to 0.96$)$ & 0.89 (0.84 to 0.95$)$ \\
\hline Neurological & 1.15 (1.08 to 1.23$)$ & 0.94 (0.87 to 1.02$)$ \\
\hline Melanoma & $1.0(0.93$ to 1.07$)$ & 0.96 (0.88 to 1.03$)$ \\
\hline Bone or soft tissue & 1.22 (1.11 to 1.33$)$ & $1.13(1.02$ to 1.24$)$ \\
\hline Endocrine & 0.97 (0.72 to 1.30$)$ & 0.90 (0.67 to 1.22$)$ \\
\hline Other & 1.05 (0.98 to 1.13$)$ & $1.02(0.94$ to 1.11$)$ \\
\hline Ambulance arrival & 3.74 (3.66 to 3.82 ) & 3.50 (3.42 to 3.59$)$ \\
\hline \multicolumn{3}{|l|}{ CTAS } \\
\hline 3 & Ref. & Ref. \\
\hline 1-2 (highest acuity) & 2.27 (2.23 to 2.31$)$ & 2.09 (2.05 to 2.14$)$ \\
\hline 4-5 (lowest acuity) & $0.19(0.18$ to 0.20$)$ & $0.29(0.28$ to 0.31$)$ \\
\hline \multicolumn{3}{|l|}{ Shift } \\
\hline Day (8:00-16:59) & Ref. & Ref. \\
\hline Evening (17:00-23:59) & 1.20 (1.17 to 1.22$)$ & 0.99 (0.96 to 1.01$)$ \\
\hline Night (0:00-7:59) & 1.22 (1.19 to 1.25$)$ & 0.94 (0.92 to 0.97$)$ \\
\hline Weekend & 0.91 (0.90 to 0.93$)$ & 0.90 (0.88 to 0.92$)$ \\
\hline
\end{tabular}




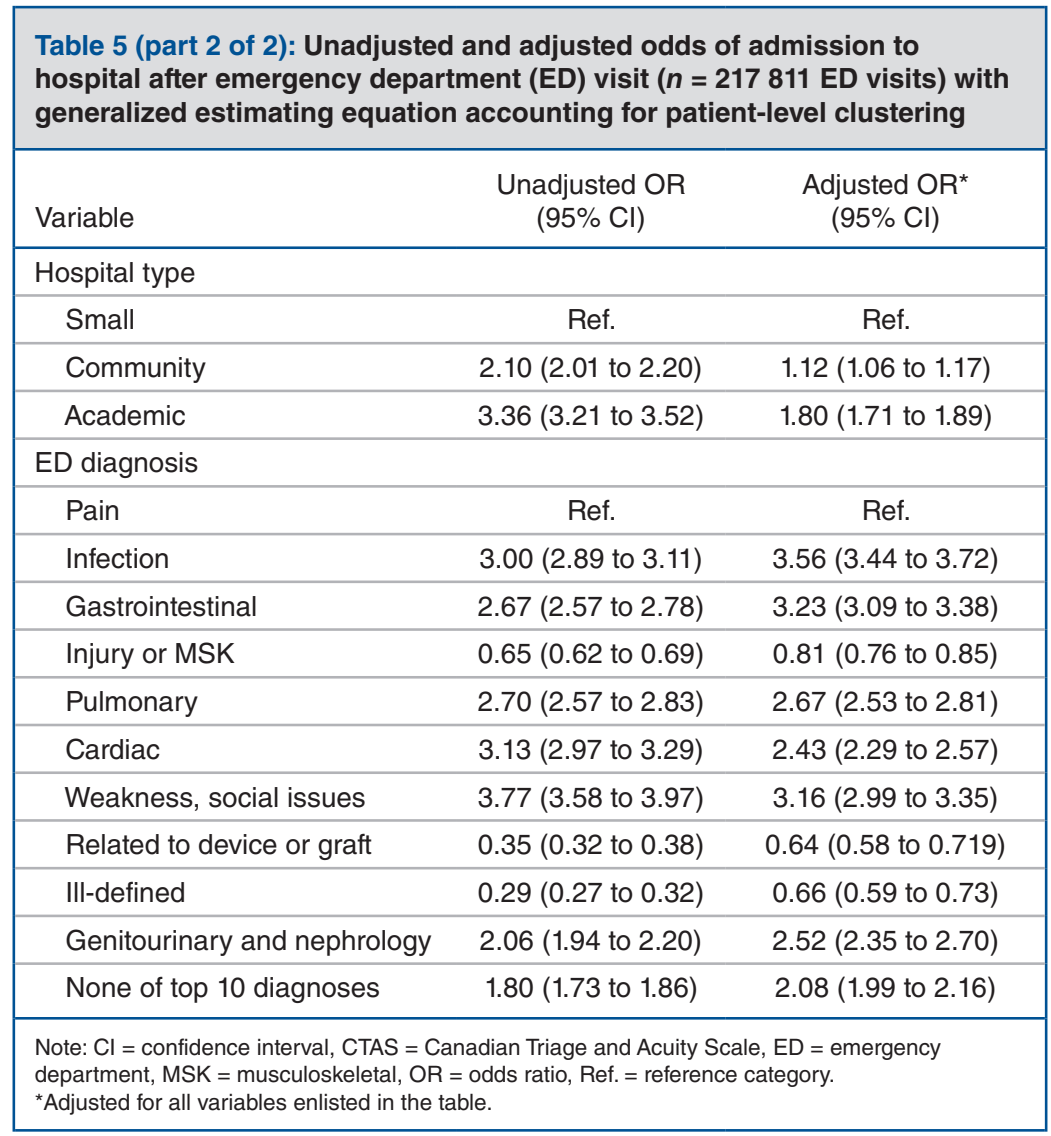

However, many studies have previously used these databases and found good agreement between chart reviews and the databases for mandatory variables ${ }^{22}$ and the main emergency department diagnosis for various diseases. ${ }^{23-25}$

In smaller communities, patients may receive scheduled treatment in the emergency department; therefore, the emergency department visit captured in this study may not have been an unexpected visit or a true emergency visit. We tried to mitigate this potential bias by excluding patients with the main diagnosis of chemotherapy or radiation therapy. We examined all emergency department visits within 30 days of chemotherapy. It was expected that most of the included emergency department visits were related to cancer or treatment adverse effects. However, some of the emergency department visits captured in this study may not result from the cancer or treatment itself. It is known that patients with cancer make far more emergency department visits than age-matched controls; ${ }^{13}$ therefore, it is expected that most emergency department visits were related to cancer or treatment.

Finally, in our analysis of hospital admission, we employed a generalized estimating equation to account for clustering within patients because of repeat visits. We did not account for clustering of visits within emergency departments because the exchangeable working correlation for clustering at the emergency department level with a generalized estimating equation was 0.009 , indicating a minimal effect of clustering. Considering that we did not account for clustering by emergency department in our analysis, the effects of emergency department characteristics may be estimated too precisely for between emergency department comparisons because of the small correlation for clustering within emergency departments and emergency department clusters of varying sizes. This could result in wider confidence intervals than what we reported for the variables with between emergency departments comparisons, such as hospital type.

\section{Conclusion}

Patients with cancer frequently use the emergency department while undergoing chemotherapy. In this Canadian, populationbased study, we found that 1 in 4 emergency department visits were for infection or fever and about one-third of emergency department visits resulted in hospital admission. The results of this study highlight opportunities for future research, including the identification of targets for future care interventions around infectious, gastrointestinal and pain diagnoses.

\section{References}

1. Canadian Cancer Statistics Advisory Committee. Canadian Cancer Statistics 2018. Toronto: Canadian Cancer Society, 2018. Available: www.cancer.ca/ Canadian-Cancer-Statistics-2018-EN (accessed 2019 July 23).

2. Table 13-10-0394-01: Leading causes of death, total population, by age group. Ottawa: Statistics Canada. Available: www.statcan.gc.ca/tables-tableaux/sum-som/ 101/cst01/hlth36a-eng.htm. Updated 2019 (accessed 2019 July 23).

3. Common Toxicity Criteria manual. Bethesda (MD): Cancer Therapy Evaluation Program; 1999.

4. Mayer DK, Travers D, Wyss A, et al. Why do patients with cancer visit emergency departments? Results of a 2008 population study in North Carolina. 7 Clin Oncol 2011;29:2683-8.

5. Brown J, Grudzen C, Kyriacou DN, et al. The emergency care of patients with cancer: setting the research agenda. Ann Emerg Med 2016;68:706-11. 
6. Fitch K, Pysenson BS. Cancer patients receiving chemotherapy: opportunities for better management. Seattle (WA): Milliman; 2010.

7. Rivera DR, Gallicchio L, Brown J, et al. Trends in adult cancer-related emergency department utilization: an analysis of data from the Nationwide Emergency Department Sample. 7AMA Oncol 2017;3:e172450.

8. Figure 8: Unplanned hospital visits after adjuvant chemotherapy. In: Quality Patient-Centred Systematic Treatment in Ontario 2014-2019: systematic treatment provincial plan. Toronto: Cancer Care Ontario. Available: www. cancercareontario.ca/sites/ccocancercare/files/assets/CCOSystemicTreatmentPlan. pdf (accessed 2019 July 19).

9. Pittman NM, Hopman WM, Mates M. Emergency room visits and hospital admission rates after curative chemotherapy for breast cancer. 7 Oncol Pract 2015;11:120-5

10. Vandyk AD, Harrison MB, Macartney G, et al. Emergency department visits for symptoms experienced by oncology patients: a systematic review. Support Care Cancer 2012;20:1589-99.

11. McKenzie H, Hayes L, White K, et al. Chemotherapy outpatients' unplanned presentations to hospital: a retrospective study. Support Care Cancer 2011; 19:963-9.

12. Emergency department (ED) visits: volumes and median length of stay by triage level, visit disposition, and main problem. Report HP17. Ottawa: Canadian Institute for Health Information; 2019. Available: https://apps.cihi.ca/ mstrapp/asp/Main.aspx?server=apmstrextprd_i.cihi.ca\&project=Quick $\% 20$ Stats\&uid=pce pub en $\&$ pwd $=\&$ evt $=2048001 \&$ visualizationMode $=0 \&$ document ID=5C3D461F11E8D6F520190080EFE53D3B\&hiddensections=header\% 2Cpath\%2CdockTop\%2CdockLeft\%2Cfooter\&_ga=2.13520311.1082733106 $.1562869000-156282843.1531919253$ (accessed 2019 July 19).

13. Enright K, Grunfeld E, Yun L, et al. Population-based assessment of emergency room visits and hospitalizations among women receiving adjuvant chemotherapy for early breast cancer. 7 Oncol Pract 2015;11:126-32.

14. Jairam V, Lee V, Park HS, et al. Treatment-related complications of systemic therapy and radiotherapy. FAMA Oncol 2019;5:1028-35.

15. Caterino JM, Adler D, Durham DD, et al. Analysis of diagnoses, symptoms, medications, and admissions among patients with cancer presenting to emergency departments. FAMA Network Open 2019;2:e190979.

16. Sawyer B, McDermott D. How does the quality of the U.S. healthcare system compare to other countries? Peterson-KFF Health System Tracker; 2019. Available: www.healthsystemtracker.org/chart-collection/quality-u-s-healthcare -system-compare-countries/\#item-start (accessed 2019 July 26).

17. Baena-Cañada JM, Estalella-Mendoza S, Rosado-Varela P, et al. Use of health-care services during chemotherapy for breast cancer. Eur 7 Cancer 2012;48:3328-34.

18. Panattoni L, Fedorenko C, Greenwood-Hickman MA, et al. Characterizing potentially preventable cancer- and chronic disease-related emergency department use in the year after treatment initiation: a regional study. F Oncol Pract 2018;14:e176-85

19. Yao J, Green B, Krzyzanowska MK. Identifying potentially preventable emergency department (PPED) visits among patients with cancer in Ontario. f Clin Oncol 2018;36(Suppl):25. doi: 10.1200/JCO.2018.36.30_suppl.25.

20. Kern WV, Cometta A, De Bock R, et al. Oral versus intravenous empirical antimicrobial therapy for fever in patients with granulocytopenia who are receiving cancer chemotherapy. International Antimicrobial Therapy Cooperative Group of the European Organization for Research and Treatment of Cancer. N Engl 7 Med 1999;341:312-8.

21. Kern WV, Marchetti O, Drgona L, et al. Oral antibiotics for fever in low-risk neutropenic patients with cancer: a double-blind, randomized, multicenter trial comparing single daily moxifloxacin with twice daily ciprofloxacin plus amoxicillin/clavulanic acid combination therapy — EORTC infectious diseases group trial XV. 7 Clin Oncol 2013;31:1149-56.

22. CIHI data quality study of Ontario emergency department visits for fiscal year 2004 2005: executive summary. Ottawa: Canadian Institute for Health Information (CIHI); 2007.

23. Atzema CL, Austin PC, Miller E, et al. A population-based description of atrial fibrillation in the emergency department: 2002 to 2010. Ann Emerg Med 2013;62:570-7.e7.

24. Masood S, Austin PC, Atzema CL. A population-based analysis of outcomes in patients with a primary diagnosis of hypertension in the emergency department. Ann Emerg Med 2016;68:258-67.e5.

25. Grewal K, Austin PC, Kapral MK, et al. Missed strokes using computed tomography imaging in patients with vertigo: population-based cohort study. Stroke 2015;46:108-13.

Affiliations: Schwartz/Reisman Emergency Medicine Institute (Grewal, McLeod, Borgundvaag), Sinai Health System; ICES Central (Grewal, Krzyzanowska, Atzema); Divisions of Emergency Medicine (Grewal, Atzema) and Medical Oncology (Krzyzanowska), Department of Medicine, University of Toronto; Division of Medical Oncology \& Hematology (Krzyzanowska), University Health Network; Department of Family \& Community Medicine (McLeod, Borgundvaag), University of Toronto; Department of Emergency Services (Atzema), Sunnybrook Health Sciences Centre, Toronto, Ont.

Contributors: All authors contributed to study conception and design, and the acquisition, analysis or interpretation of data. Keerat Grewal and Clare Atzema drafted the manuscript. All authors contributed to editing and revising the manuscript. Keerat Grewal had full access to all the data in the study and performed the statistical analysis. Clare Atzema supervised the study. All authors gave final approval of the version to be published and agreed to be accountable for all aspects of the work.

Data sharing: The data set from this study is held securely in coded form at ICES. While data sharing agreements prohibit ICES from making the data set publicly available, access may be granted to those who meet prespecified criteria for confidential access, available at www.ices.on.ca/DAS. The full data set creation plan and underlying analytic code are available from the authors upon request, understanding that the computer programs may rely upon coding templates or macros that are unique to ICES and are therefore either inaccessible or may require modification.

Supplemental information: For reviewer comments and the original submission of this manuscript, please see www.cmajopen.ca/content/8/3/ E496/suppl/DC1.

Disclaimer: This study was supported by ICES, which is funded by an annual grant from the Ontario Ministry of Health and Long-Term Care (MOHLTC). Parts of this material are based on data and information compiled and provided by MOHLTC, CIHI and Cancer Care Ontario. The analyses, conclusions, opinions and statements expressed herein are solely those of the authors and do not reflect those of the funding or data sources; no endorsement is intended or should be inferred. 